\title{
TABOOS AND MYTHS REGARDING BREASTFEEDING PRACTICES IN PREGNANT POPULATION
}

\author{
Faiza Ibrar, Naila Khurshid, Saima Qamar*, Atikka Masud, Bushra Iftikhar*, Seema Gul** \\ Fauji Foundation Hospital, Rawalpindi Pakistan, *Fatima Memorial Hospital, Lahore Pakistan, **Pakistan Naval Ship Shifa Hospital, Karachi Pakistan, \\ ${ }^{* *}$ Watim Medical and Dental College, Rawalpindi Pakistan
}

\begin{abstract}
Objective: To determine the taboos and myths regarding breastfeeding practices in our pregnant population.

Study Design: Cross-sectional study.

Place and Duration of Study: Obstetrics and Gynecology Department, Fauji Foundation Hospital, Rawalpindi Pakistan, from May to Oct 2018.

Methodology: A total of 100 pregnant women attending antenatal clinics were included in the study using non-probability purposive sampling technique. Taboos and myths regarding breast feeding practices were determined using self-administered questionnaire on 2-point Likert scale (1=agree \& $2=$ disagree).

Results: A total of 100 pregnant women participated in the study. Mean parity was $2.89 \pm 1.75$ and gravidity was $4.17 \pm 2.04$. Most of the mothers (90\%) were house wives and received information regarding breast feeding from family members (81\%). Mothers were aware of the nutritious value of breast milk as compared to formula milk. However, there were myths that were not evidence based. These include: breasts sag with breast feeding (48\%), it is not necessary to breast feed the baby during night time $(43 \%)$, breast milk alone was not sufficient to satisfy the child $(51 \%)$, small size breast produce insufficient milk (27\%).

Conclusion: Participants of this study are aware of the importance of breast feeding. However, there are certain taboos and myths prevailing in our population which are not proven scientifically.
\end{abstract}

Keywords: Breast feeding, Exclusive breast feeding, Myths, Pregnancy, Taboos.

How to Cite This Article: Ibrar F, Khurshid N, Qamar S, Masud A, Iftikhar B, Gul S. Taboos and Myths Regarding Breastfeeding Practices in Pregnant Population. Pak Armed Forces Med J 2021; 71(5): 1647-1650. doi: https://doi.org/10.51253/pafmj.v71i5.4765

This is an Open Access article distributed under the terms of the Creative Commons Attribution License (https://creativecommons.org/licenses/by-nc/4.0/), which permits unrestricted use, distribution, and reproduction in any medium, provided the original work is properly cited.

\section{INTRODUCTION}

Breast milk is unique, ideal and valuable food for a child. ${ }^{1}$ It cannot be replaced with any other diet as it contains all essential nutrients that are required for the growth and development of the infants. 2,3 According to World Health Organization (WHO), approximately 9 million children under five die every year. Nearly $70 \%$ of these deaths are attributed to preventable causes like pneumonia and diarrhea in neonatal period and over one third occur due to malnutrition. The situation is worse in developing countries. ${ }^{4}$ WHO estimated that optimal breast feeding can prevent $13 \%$ of under-five mortality. ${ }^{5}$ This along with proper diet can reduce children death by $19 \%{ }^{6}$

Globally, 39\% of the infants receive exclusive breast feeding in first six months of life ${ }^{7}$. However, the prevalence was found to be low in some developing countries $^{6}$. This may be due to lack of awareness, introduction of artificial feed, early initiation of weaning,

Correspondence: Dr Faiza Ibrar Professor of Obstetrics \& Gynaecology, Fauji Foundation Hospital, Rawalpindi Pakistan

Received: 09 Jul 2020; revision received: 28 Sep 2020; accepted: 01 Oct 2020 lack of counseling by health care providers at prenatal visits, educational background and cultural beliefs of the parents and family members. 8,9

Infant feeding practices should be observed closely to take appropriate action in time, to ensure proper growth and development of the child. The purpose of present study was to determine taboos and myths regarding breast feeding in pregnant women presenting in outpatient department at Fauji Foundation Hospital. This information will be useful for policy makers to formulate interventional program regarding maternal and child health care in future.

\section{METHODOLOGY}

A cross-sectional study was conducted in Obstetrics and Gynecology department, Fauji Foundation Hospital, Rawalpindi, from May to October 2018. Sample size was calculated using WHO with a sample size calculator, with a confidence level of $95 \%$, anticipated population proportion of $62 \%, 10$ absolute precision required of $10 \%$, the sample size (n) was 100 cases.

Inclusion Criteria: Pregnant women attending antenatal clinics were included in the study using nonprobability purposive sampling technique. 
Exclusion Criteria: Those women who were using recreational drugs or conceived as a result of rape.

A 22-item self-administered questionnaire was developed based on literature review and input from stakeholders. It was 2-point Likert scale (1=agree, $2=$ disagree) evaluating taboos and myths regarding breast feeding in pregnant women. Questionnaire and informed consent were drafted in English and Urdu after approval from hospital ethical committee Ref No 405/ERC/FFH/RWP. Questionnaire was printed and distributed to study participants who met the inclusion criteria. An informed written consent was taken from all the participants. Confidentiality of participants was maintained.

Data was analyzed using Statistical package for Social Sciences (SPSS) version 21. Mean \pm standard deviation was calculated for continuous variables. Frequency and percentages were calculated for categorical variables.

\section{RESULTS}

A total of 100 pregnant women participated in the study. Mean parity was $2.89 \pm 1.75$ and gravidity was $4.17 \pm 2.04$ (Table-I).

Almost half $(51 \%)$ received education till matric and $49 \%$ were graduates and postgraduates. Most of the mothers $(90 \%)$ were house wives and $10 \%$ were working women. More than half $(53 \%)$ lived in joint family system while half of mothers $(54 \%)$ had per capita income of $\leq 3000$ Rupees. The source of information regarding breast feeding beliefs mainly came from family member $(81 \%)$ and some contribution from health care providers (19\%). Majority of these women $(77 \%)$

Table- I: Descriptive Statistics ( $\mathrm{n}=100)$.

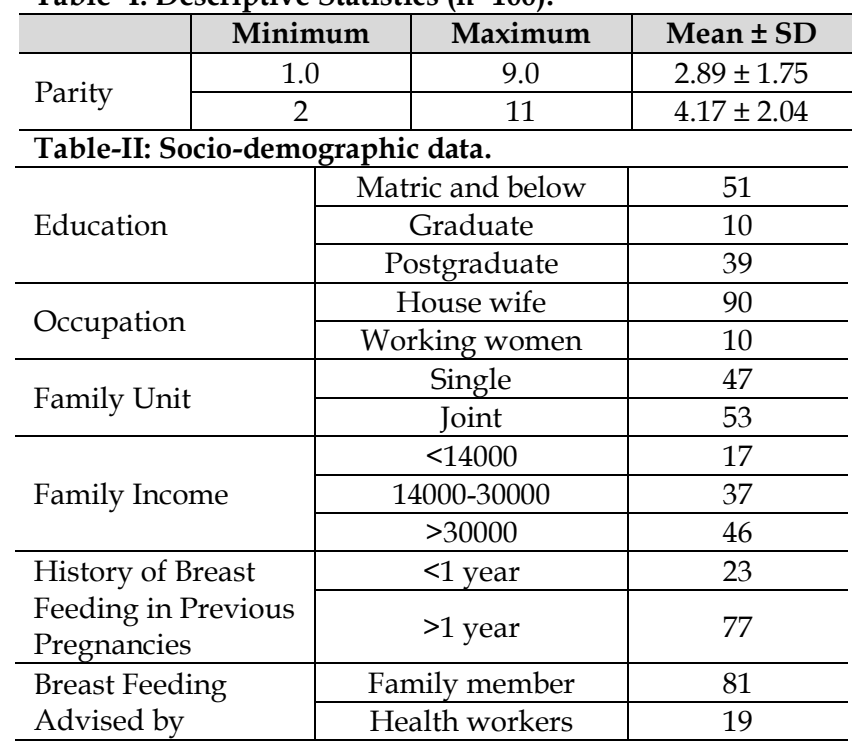

have history of breast feeding their babies in for more than one year while $23 \%$ for less than 1 year. The sociodemographic profile of the participants is illustrated in Table-II. Table-III explains all the myths regarding breast feeding practices.

Table-III: Taboos and myths regarding breast feeding in pregnant women.

\begin{tabular}{|c|c|c|}
\hline Particulars & Agree & Disagree \\
\hline \multicolumn{3}{|l|}{ Do you feel that } \\
\hline $\begin{array}{l}\text { Milk let down does not occur } \\
\text { within first few days after birth }\end{array}$ & $54(54 \%)$ & $46(46 \%)$ \\
\hline Breast feeding is painful & $18(18 \%)$ & $82(82 \%)$ \\
\hline $\begin{array}{l}\text { Breast milk is not sufficient for } \\
\text { baby }\end{array}$ & $51(51 \%)$ & $49(49 \%)$ \\
\hline $\begin{array}{l}\text { Breast feeding should be done } \\
\text { every 3-4 hours }\end{array}$ & $91(91 \%)$ & $9(9 \%)$ \\
\hline $\begin{array}{l}\text { Breast milk decreases with } \\
\text { repeated feeding }\end{array}$ & $31(31 \%)$ & $69(69 \%)$ \\
\hline $\begin{array}{l}\text { It is not necessary to breast feed the } \\
\text { baby during night time }\end{array}$ & $43(43 \%)$ & $57(57 \%)$ \\
\hline $\begin{array}{l}\text { Feed the baby from both breasts } \\
\text { equally }\end{array}$ & $99(99 \%)$ & $1(1 \%)$ \\
\hline $\begin{array}{l}\text { Breast refilling takes some time } \\
\text { after feeding the baby }\end{array}$ & $60(60 \%)$ & $40(40 \%)$ \\
\hline $\begin{array}{l}\text { There is any method which can } \\
\text { determine satisfaction of baby with } \\
\text { mother's milk }\end{array}$ & $57(57 \%)$ & $43(43 \%)$ \\
\hline $\begin{array}{l}\text { Formula milk has nutritious value } \\
\text { similar to breast milk }\end{array}$ & $5(5 \%)$ & $95(95 \%)$ \\
\hline $\begin{array}{l}\text { Small sized breasts cannot produce } \\
\text { sufficient milk }\end{array}$ & $27(27 \%)$ & $73(73 \%)$ \\
\hline Inverted nipples hampers feeding & $37(37 \%)$ & $63(63 \%)$ \\
\hline $\begin{array}{l}\text { Breast fed babies feel more } \\
\text { abdominal discomfort }\end{array}$ & $9(9 \%)$ & $91(91 \%)$ \\
\hline Lactation stops menstruation & $44(44 \%)$ & $56(56 \%)$ \\
\hline $\begin{array}{l}\text { Lactating mothers should take } \\
\text { balanced diet }\end{array}$ & $93(93 \%)$ & $7(7 \%)$ \\
\hline $\begin{array}{l}\text { Lactating mothers should not use } \\
\text { medications without prescription }\end{array}$ & $55(55 \%)$ & $45(45 \%)$ \\
\hline $\begin{array}{l}\text { Mothers during their sickness } \\
\text { should not breast feed their babies }\end{array}$ & $54(54 \%)$ & $46(46 \%)$ \\
\hline $\begin{array}{l}\text { Babies having vomiting and } \\
\text { diarrhea should not be fed with } \\
\text { breast milk }\end{array}$ & $36(36 \%)$ & $65(65 \%)$ \\
\hline $\begin{array}{l}\text { Formula milk should be started } \\
\text { after } 6 \text { months of age }\end{array}$ & $29(29 \%)$ & $71(71 \%)$ \\
\hline $\begin{array}{l}\text { Breast feeding is natural } \\
\text { contraceptive }\end{array}$ & $58(58 \%)$ & $42(42 \%)$ \\
\hline $\begin{array}{l}\text { Breast feeding should be stopped } \\
\text { after } 12 \text { months }\end{array}$ & $11(11 \%)$ & $89(89 \%)$ \\
\hline Breasts sag with breast feeding & $48(48 \%)$ & $52(52 \%)$ \\
\hline
\end{tabular}

\section{DISCUSSION}

Present study is one of the first to our knowledge provide information on taboos and myths regarding breast feeding in Pakistani pregnant women. The study shows some of the myths that are scientifically 
not proven. Certain beliefs in our findings were closely related to previous literature, that majority of mothers believe that breasts sag with lactation. ${ }^{10,11}$

Our findings suggest that mother were aware of the fact that nutritious value of formula milk is less than breast milk but still $29 \%$ of the mothers agreed to start formula milk after 6 months of age. This could be explained by the fact that in our study more than half of the mothers (51\%) felt that breast milk alone was not sufficient to satisfy the child and they were not ready to give breast milk to their child in night time. Research shows that only $5 \%$ of the mothers actually suffer from physiologically insufficient supply of milk. ${ }^{12}$ However, $71 \%$ of the mothers felt that breast feeding should continue beyond 6 months of age. Furthermore, $89 \%$ of the mothers disagreed to discontinue breast feeding after 12 months of age. This is contrary to industrialized countries where few babies are breast fed beyond six months of age. ${ }^{13}$ This difference is due to strong family support especially from mother and mother in law in our culture, as majority of mothers lived in joint family system (53\%) and advice regarding breast feeding mainly came from family members in our study. Moreover, mothers were mostly house wives $(90 \%)$ so they would have enough time to breast feed their children. In developed countries like United states where mother are mostly working and there is no policy to provide them paid maternity leave so mothers cannot continue breast feeding. ${ }^{14}$

Lactation has contraceptive advantage as reported by $58 \%$ of the women. This is comparable to a published study in India where contraceptive advantage of breast feeding was reported in $42 \%$ of the cases. ${ }^{9}$

Mothers believed that breast feeding should be discontinued while child had diarrhea and vomiting $(35 \%)$. Research shows that breast milk not only prevent diarrhea and vomiting in feeding infants but continuous feeding after every episode can reduce dehydration, electrolyte imbalance and weight loss in child. ${ }^{15}$ Some participants in our study felt that that small sized breast produce insufficient milk (27\%). A study conducted in Poland showed that breast volume does not affect quality and quantity of breast milk. ${ }^{16}$

Majority of mothers in our study were of the opinion that child should be fed every 3-4 hours, it is not necessary to breast fed during night time and breast milk decreases with repeated feeding. This is contrary to research findings showing that infants should be fed on demand during day and night times instead of sticking to average number of time which may not be appropriate for mother and child. ${ }^{17}$

In our study, most of the participants learnt their beliefs regarding breast feeding practices from family members in $81 \%$ and health care providers in $19 \%$ of the cases. This is similar to a study conducted in Kenya where the beliefs regarding breast feeding practices were learnt from family members. ${ }^{18}$ Generally, in our population pregnant and breast feeding mothers tend to feed their babies according to myths transferred from generation to generation. Majority of mothers in our study had experience of feeding their children with breast milk for more than one year. The adjustments in beliefs and practices regarding breast feeding are adapted without taking advice from nutritionist and medical professionals. It is the responsibility of perinatal health care providers to play their role in changing taboos and myths regarding breast feeding during their visit to antenatal clinics. It is essential to educate pregnant women and their family members regarding health benefits of breast feeding for mother and baby in the context of a particular culture and rooted beliefs.

\section{LIMITATION OF STUDY}

The limitation of the study was its small sample size and it was conducted within a single institution. It is therefore recommended to conduct similar studies with large sample size in multiple institutions and also in other provinces, countries and cultures, so as to generalize the findings of the study.

\section{CONCLUSION}

Participants of this study are aware of the importance of breast feeding. However, there are certain taboos and myths prevailing in our population, most of the information gained by neighbor and elderly woman. It is therefore, essential to educate mothers during pre-natal period, regarding breast feeding practices, emphasize the significance of breast feeding and counsel them to dissipate wrong beliefs and myths from their minds.

\section{ACKNOWLEDGEMENT}

We are grateful to our Bio-statistician, Mr. Aamir Afzal Foundation University, Islamabad Campus for his valuable input.

\section{Conflict of Interest: None.}

\section{Authors' Contribution}

FI: Direct intellectual to conception, design, analysis and interpretation, NK: Direct intellectual to conception, design, analysis and interpretation, SQ: Direct intellectual to conception, design, analysis and interpretation, AM: Direct intellectual to conception, design, analysis and interpretation, BI: Direct intellectual to conception, design, analysis and 


\section{Breastfeeding Practices}

interpretation, SG: Direct intellectual to conception, design, analysis and interpretation.

\section{REFERENCES}

1. Martin CR, Ling PR, Blackburn GL. Review of infant feeding: Key features of breast milk and infant formula. Nutrien 2016; 8(5): 1-11.

2. Billeaud C. Breast Milk Substitutes: Changing Ideas. J Food Sci Eng 2018; 8(6): 231-236.

3. Alimoradi F, Javadi M, Barikani A, Kalantari N. An overview of importance of breastfeeding. J Compr Pediatr 2014; 4(2): e14028.

4. WHO. WHO|Child mortality [Internet]. Partnership for Maternal, Newborn \& Child Health. 2011. [Internet] Available from: http://www.who.int/pmnch/media/press_materials/fs /fs_mdg4_childmortality/en/ (Accessed on October 15, 2018)

5. Bora R. Breast Feeding in Developing Countries: Is There a Scope for Improvement. J Neonatal Biol 2016; 5(1): 1-5.

6. Daglas M, Antoniou E. Cultural views and practices related to breastfeeding. Heal Sci J 2012; 6(2): 353-361.

7. WHO/UNICEF. Global Nutrion Target 2025. Breastfeeding Policy. 2018, [Internet] Available from: https://apps.who.int /iris/handle/ 10665/149022. (Accessed on October 15, 2018)

8. Jiang H, Li M, Yang D, Wen LM. Awareness, intention, and needs regarding breastfeeding: Findings from first-time mothers in Shanghai, China. Breastfeed Med 2012; 7(1): 526-534.

9. Kamath SP, Garg D, Khan MK, Jain A, Baliga BS. Perceptions and Practices regarding Breastfeeding among Postnatal Women at a District Tertiary Referral Government Hospital in Southern India. Scientifica (Cairo) 2016; 2016(2): 5430164.
10. Tyndall JA, Kamai R, Chanchangi D. Knowledge, attitudes and practices on exclusive breastfeeding in adamawa, Nigeria. Am J Public Heal Res 2016; 4(3): 112-119.

11. Rinker B, Veneracion M, Walsh CP. The Effect of Breastfeeding on Breast Aesthetics. Aesthetic Surg J 2008; 28(5): 534-537.

12. Dieterich CM, Felice JP, O'Sullivan E, Rasmussen KM. Breastfeeding and Health Outcomes for the Mother-Infant Dyad. Pediatr Clin North Am 2013; 60(1): 31-48.

13. Mylod D. Breast feeding a sick child; Can social media influence practice?. Compr Child Adolesc Nurs 2015; 38(2): 77-84.

14. Al Ketbi MI, Al Noman S, Al Ali A, Darwish E, Al Fahim M, Rajah J. Knowledge, attitudes, and practices of breastfeeding among women visiting primary healthcare clinics on the island of Abu Dhabi. United Arab Emirates 2018; 13(2): 26-30.

15. Santos FS, Santos LH dos, Saldan PC, Santos FCS, Leite AM, Mello DF de. Breastfeeding and Acute Diarrhea Among Children Enrolled in the Family Health Strategy. Texto Contexto Enferm 2016; 25(1): e0220015

16. Żelaźniewicz A, Pawłowski B. Maternal breast volume in pregnancy and lactation capacity. Am J Phys Anthropol 2018; 168(1): 180-189.

17. Kent JC, Mitoulas LR, Cregan MD, Ramsay DT, Doherty DA, Hartmann PE. Volume and frequency of breastfeedings and fat content of breast milk throughout the day. Pediat 2006; 117(3): e387-e395.

18. Wanjohi M, Griffiths P, Wekesah F, Muriuki P, Muhia N, Musoke RN, et al. Sociocultural factors influencing breastfeeding practices in two slums in Nairobi, Kenya. Int Breastfeed J 2016; 5(2): $12-18$. 